Fanum

Sociológico

\section{Forum Sociológico}

Série II

28 | 2016

Interculturalidade e educação

\title{
A inclusão de minorias no desenho de territórios educativos interculturais : reflexões a partir do Projecto ALLMEET
}

The inclusion of minority groups in the design of intercultural pedagogic territories : reflecting from ALLMEET Project

Inês Vieira, Cláudia Urbano, Maria do Carmo Vieira da Silva e Luís Baptista

\section{OpenEdition}

Journals

Edição electrónica

URL: https://journals.openedition.org/sociologico/1376

DOI: $10.4000 /$ sociologico.1376

ISSN: 2182-7427

Editora

CICS.NOVA - Centro Interdisciplinar de Ciências Sociais da Universidade Nova de Lisboa

\section{Refêrencia eletrónica}

Inês Vieira, Cláudia Urbano, Maria do Carmo Vieira da Silva e Luís Baptista, «A inclusão de minorias no desenho de territórios educativos interculturais : reflexões a partir do Projecto ALLMEET», Forum Sociológico [Online], 28 | 2016, posto online no dia 31 dezembro 2016, consultado o 31 março 2022.

URL: http://journals.openedition.org/sociologico/1376 ; DOI: https://doi.org/10.4000/sociologico. 1376 


\title{
A INCLUSÃO DE MINORIAS NO DESENHO DE TERRITÓRIOS EDUCATIVOS INTERCULTURAIS: REFLEXÕES A PARTIR DO PROJECTO ALLMEET THE INCLUSION OF MINORITY GROUPS IN THE DESIGN OF INTERCULTURAL PEDAGOGIC TERRITORIES: REFLECTING FROM ALLMEET PROJECT
}

\author{
Inês Vieira \\ Cláudia Urbano \\ Maria do Carmo Vieira da Silva \\ Luís Baptista \\ Universidade Nova de Lisboa, Faculdade de Ciências Sociais e Humanas, Centro Interdisciplinar de Ciências Sociais \\ (CICS.NOVA)
}

\begin{abstract}
Resumo
Num contexto de diversidade de grupos populacionais em convivência, acelerado pelos processos de globalização das mobilidades, o diálogo intercultural vem-se afirmando como processo educativo de sucesso para o respeito da diversidade e a promoção da coesão social. Considerado uma boa prática da União Europeia (UE), o diálogo intercultural está na base da proposta do projecto ALLMEET, que prevê a implementação de plataformas educativas interculturais em contextos urbanos diferenciados de cinco regiões da Federação Russa. A reflexão e a partilha de experiências no âmbito da rede de trabalho constituída neste projecto conduziu-nos a uma discussão sobre as finalidades educativas e seu enquadramento de grupos minoritários, a criação de territórios educativos prioritários e a interculturalidade em contexto de desigualdades sociais.
\end{abstract}

Palavras-chave: União Europeia - Federação Russa, educação intercultural, territórios educativos interculturais, redes de investigação

\begin{abstract}
In a context of sociability of diverse population groups, intercultural dialogue has been affirming as a successful educational idea for the respect of diversity and for the promotion of social cohesion. Considered among the best practices of the European Union, intercultural dialogue is at the basis of the proposal of ALLMEET project, which aims to implement intercultural education platforms in different urban contexts of five regions in Russian Federation. The debate and sharing experiences, within the network constituted in this project, led us to a discussion about educational aims and their framing of minority groups, the creation of priority education territories, and interculturalism in a context of social inequity.
\end{abstract}

Keywords: European Union - Russian Federation, intercultural education, intercultural education territories, research networks

\section{Introdução}

O princípio da inclusão permeia o desenho dos territórios educativos, às escalas portuguesa e europeia, há várias décadas. Educação e inclusão são considerados dois pilares de base das sociedades democráticas, num contexto de crescente diversidade de grupos populacionais em convivência, acelerado pelos processos de globalização das mobilidades. A presença de grupos minoritários origina desafios 
importantes ao nível da promoção da diversidade cultural em contexto de dominação cultural e linguística da sociedade de acolhimento. É neste contexto que o diálogo intercultural tem vindo a afirmar-se como processo educativo de sucesso para a promoção do respeito pela diversidade e a coesão social.

Como abordagem para a observação da realidade social, a perspectiva intercultural promove a interrogação e reflexão sobre conceitos, leis, organizações, estruturas, processos sociais e dimensões relacionais em torno da diversidade cultural (FCSH/ /UNL, 2015a). Como abordagem para a intervenção educativa, a educação intercultural beneficia desta observação, reconhecendo e monitorizando alterações e desenvolvimentos das condições sociais, propondo e implementando abordagens actualizadas para lidar com a diversidade cultural, linguística, étnica, religiosa, entre outras.

Importa reconhecer que a interculturalidade inclui uma proposição sociopolítica e ética de promoção do diálogo na diversidade cultural. Propõe-se ultrapassar o carácter estático do multiculturalismo, no qual se constata a existência de grupos étnicos e culturais diferenciados, coexistentes sem criação de um sentido comum de cidadania, e passível de modelos de integração criticados pela sua tendência segregadora ou assimilacionista. Em contraponto, o projecto intercultural propõe a criação de uma nova síntese cultural a partir das culturas presentes, que se acredita poderem incorporar e reforçar a cultura nacional da sociedade de acolhimento, promovendo a coesão social (Malgesini e Giménez, 2000).

Se a interculturalidade é um projecto sociopolítico de largo espectro, a sua realização educativa terá de superar as estruturas formais da educação escolar (Urbano et al., 2016), o que requer a observação das características territoriais e comunitárias para o desenvolvimento de uma intervenção contextualmente informada. A ideia de uma intervenção pedagógica em comunidades para além do espaço escolar restrito tem sido particularmente desenvolvida ao nível da educação social, partindo de uma concepção de educação permanente, tanto em escolas como em contextos não-formais e informais de formação e de vida (Tramma, 1999). A própria concepção da escola portuguesa como "comunidade educativa", dialogante e interventiva na resolução de problemas, acentua este propósito (Portaria n. 0 309/2008 de 22 de Abril), como forma de "Incentivar novas formas de parceria educativa com os pais e as comunidades educativas, quer através da sua efectiva participação e corresponsabilização na administração das escolas, quer através de formas de voluntariado sócio-educativo" (Documento Orientador do Ensino Básico de 1998).

Os conceitos de território e comunidade podem contribuir para uma compreensão mais integrada de territórios educativos em contexto de diversidade social e cultural. Appadurai (1996), reflectindo sobre as comunidades imaginadas num contexto de economia cultural global (muito marcada pela tensão entre homogeneização e heterogeneização cultural), considera cinco dimensões ou paisagens das comunidades, das quais destacamos a importância das ethnoscapes, paisagens de pessoas em movimento, envolvendo diferentes grupos em mobilidade e afectando as políticas nacionais a um nível sem precedentes (Appadurai, 1996: 33-36). Ultrapassando o ideário de "comunidade" enquanto algo invariavelmente bom, emocionalmente apelativo e definido de acordo com diferentes ideias subjectivas de comunidade enquanto "boa vida", Newby (1980) sugere mais três sentidos conferidos a "comunidade": (1) associada a uma localidade fixa e circunscrita, aproximando-se do conceito de território; (2) considerada um sistema social local, uma rede de pessoas interconectadas com diferentes tipos de relações entre elas; (3) um tipo de relação, um sentido de identidade ou comunhão entre indivíduos.

Do conceito de território destacamos o sentido de contextualização através da sua delimitação física, que nos permite observar a "inscrição física da vida social", sendo que "o espaço não é protagonista da vida social, mas o seu resultado pela acção dos diferentes grupos sociais que dele se apropriam, o moldam, Ihe dão sentido e valor social" (Baptista, 2016: 225). O conceito de território permite, por isso, observar que o trabalho sobre determinado espaço não pode ser reduzido à sua dimensão física, alertando a atenção, por exemplo, para dimensões de poder e cultura (práticas simbólicas partilhadas, experienciadas de modo diferenciado).

Território e comunidade não devem ser considerados conceitos sinónimos, mas sim complementares enquanto referências para uma intervenção educativa contextualizada e inclusiva. Nesta perspectiva de comunidade atenta e estruturada em torno do poder, das características do território e das suas marcas de construção de fronteiras, a questão da diversidade social e cultural pode, assim, ser explorada como uma chave de leitura sustentada. Esta chave territorial e comunitária não ignora dinâmicas de inclusão e exclusão, o que permite mapear criticamente as necessidades de intervenção educativa, entre outros níveis de possível necessidade de intervenção.

A educação intercultural posiciona-se na defesa da diversidade de culturas, seus valores, interacções e línguas, reforçando a solidariedade entre contextos com diferentes níveis de recursos (Silva, 2008). Neste sentido, torna-se importante conhecer as dimensões territoriais e comunitárias previamente referenciadas, permitindo a avaliação das condições existentes a três níveis: características do território de referência; redes sociais no território; tipos de relações sociais e desafios interculturais emergentes. Deste modo, a educação intercultural pode substanciar-se 
numa acção dupla, tanto no plano do acolhimento e integração dos "representantes" da diversidade cultural (imigrantes ou outros grupos populacionais), como no plano dos autóctones/maioria cultural, desconstruindo potenciais conflitos emergentes do medo da diversidade (Genovese, 2003).

\section{Abordagem metodológica}

A ideia de interculturalidade é apontada como geradora de boas práticas europeias a promover em países vizinhos. Neste enquadramento, o projecto ALLMEET - Actions of Lifelong Learning addressing Multicultural Education and Tolerance in Russia (544410-TEMPUS-1-2013-IT-TEMPUS-JPHS) foi co-financiado ao abrigo do programa Tempus da União Europeia de 2013 a 2016. Este projecto previa a implementação de plataformas educativas interculturais em contextos urbanos diferenciados de cinco regiões da Federação Russa. O presente artigo surge na recta final do projecto ALLMEET, no qual os quatro autores colaboram, tendo acompanhado com particular proximidade a definição do estado da arte sobre interculturalidade e educação ao longo da vida nos diferentes contextos da União Europeia e da Federação Russa das delegações parceiras.

Partimos da recolha de informação sobre características territoriais, grupos minoritários e áreas de intervenção prioritária para as Plataformas Educativas Interculturais promovidas pelo projecto ALLMEET e correspondentes a contextos diferenciados na Federação Russa. Esta recolha foi feita por cada equipa russa, sendo posteriormente revista e sintetizada pela equipa portuguesa (FCSH/UNL, 2015b; 2015c). Importa referir que esta informação pode ser mobilizada para a promoção de pistas de reflexão sobre a interculturalidade e seus desafios, não devendo, porém, ser tomada enquanto relatório descritivo das realidades sociais em contexto russo; não é esse o objectivo, nem o alcance do projecto ALLMEET, nem tão pouco a pretensão dos autores deste artigo.

Neste seguimento, a partir das pistas de reflexão sobre desafios territoriais, grupos minoritários e áreas de intervenção prioritária (particularmente na Área Metropolitana de Lisboa, território de enquadramento da equipa portuguesa participante no projecto) procuraremos sugerir, de acordo com a realidade social e educativa portuguesa, direcções de desenvolvimento intercultural (Vieira et al., 2016a; 2016b). Reflectiremos sobre como estas ideias se traduzem e integram numa rede de instituições de investigação, formação e educação superior em diálogo União Europeia - Federação Russa. Proporemos uma reflexão sobre possibilidades de trabalho e mobilização do campo conceptual da educação intercultural para o desenho de territórios educativos, articulada numa discussão sobre as finalidades educativas e seu enquadramento de grupos minoritários, a criação de territórios educativos prioritários e a interculturalidade em contexto de desigualdades sociais.

\section{Territórios, grupos minoritários e áreas de intervenção prioritária}

No âmbito do projecto ALLMEET, após a análise de todos os relatórios e recomendações regionais elaborados pelas equipas russas, foi redigido um relatório síntese para a análise comparativa dos desafios interculturais (FCSH/UNL, 2015b). Neste salientam-se componentes importantes para o conhecimento dos territórios e das dinâmicas relacionadas com a diversidade populacional, pelo que procedemos, de seguida, a breves apresentações.

A Plataforma Educativa Intercultural (IEP) de Yoshkar-Ola situa-se na República de Mari $\mathrm{El}$, região multi-étnica (etnias russa e mari com número semelhante de população, para além de número significativo da etnia tártara) predominantemente mono-religiosa (igreja Ortodoxa Cristã russa). Nesta república existe igualdade nominal das línguas e dos direitos linguísticos dos cidadãos, assumindo-se, porém, a prevalência da língua russa. Apesar de existirem programas de prevenção de conflitos étnicos, verificam-se algumas atitudes anti-migratórias por parte dos jovens de Mari. Receia-se que a adaptação nacional de uma lei federal que proíbe algumas actividades a trabalhadores estrangeiros (a proibição não existe para cidadãos russos) possa fomentar conflitos entre as culturas residentes.

$\mathrm{Na}$ República do Tartaristão o planeamento das actividades da IEP tem sido feito em três cidades de dimensões e histórias bastante diferentes: Kazan, Naberezhnye Chelny e Elabuga. Trata-se de uma região multi-étnica e multi-confessional, com número semelhante de pessoas da etnia russa (e religião Cristã Ortodoxa) e da etnia tártara (e religião Muçulmana Sunni), região muito atractiva para trabalhadores imigrantes, particularmente provenientes de antigos países da URSS. A maioria dos imigrantes reside nas maiores cidades e começam a formar-se os primeiros enclaves. Os principais desafios interculturais dizem respeito a manifestações de conflito étnico e confessional no espaço digital (incluindo contra imigrantes) e a conflitos baseados na língua tártara, à qual se atribui importância significativa ao nível escolar, mas que não é praticamente usada na esfera pública.

A IEP de Arkhangelsk situa-se na região do Norte Árctico, longe das maiores cidades russas, com uma população de perfil étnico relativamente homogéneo e um baixo número de imigrantes. Apesar de raros, são conhecidos casos de discriminação com base em traços étnicos ou culturais, sobretudo 
de jovens russos contra trabalhadores imigrantes (particularmente através de expressões extremistas de intolerância étnica e cultural via internet). Está em curso um conjunto de políticas e actividades (envolvendo organizações públicas e associações) para fortalecer a cooperação entre diferentes grupos étnicos e prevenir conflitos étnicos e xenofobia.

A IEP de Krasnoyarsk situa-se na região da Sibéria, território multi-étnico ao nível de populações indígenas. Apesar de ser identificada como a região com menores índices de intolerância cultural da Federação Russa, a população em geral apresenta atitudes relativamente negativas face a imigrantes. Estas atitudes são reforçadas por uma imagem mediática pouco favorável às relações interétnicas. Verifica-se a presença de imigrantes indocumentados e o peso crescente de redes de imigrantes de diferentes nacionalidades. Uma das barreiras à integração da crescente população imigrante é a falta de conhecimento da língua russa.

A delegação da metrópole moscovita, território da capital russa, refere que apesar da crescente diversidade de grupos populacionais em mobilidade (para efeitos de turismo, trabalho em sectores diferenciados, educação, media) para além do crescente número de imigrantes e refugiados, não se observa a formação de enclaves étnicos. O carácter problemático da crescente taxa de desemprego (abrangendo toda a população) e de discursos mais populistas aumenta a percepção da população geral sobre os imigrantes enquanto grupo indesejado, o que se vê reforçado pela associação construída (até em fontes oficiais) entre migrações e criminalidade.

Procurando sintetizar outras observações sobre grupos minoritários nos documentos de referência, é possível destacar um conjunto de grupos populacionais diferenciados, num sentido que não corresponde à ideia de matriz europeia de "emergência multicultural" enquanto diversidade étnica-cultural decorrente quase exclusivamente das migrações e do seu papel na complexificação das sociabilidades. As populações imigrantes constituem um desafio percepcionado como novo e emergente, face ao qual é necessário construir conhecimento que promova uma intervenção informada. Porém, a diversidade apontada como objecto de estudo prévio e objectivo de reforço de tolerância diz respeito, essencialmente, a populações autóctones da Federação Russa. Diferentes religiões (cristã ortodoxa, cristã católica, cristã protestante, judaica, islâmica, budista, entre muitas outras), diferentes línguas (algumas oficiais, como a língua tártara no Tartaristão), e outras não oficiais - entre línguas da Federação Russa e de grupos imigrantes -, todas com menos direitos que a língua maioritária russa), diferentes grupos étnicos indígenas dos territórios considerados ou de outros territórios da Federação Russa são apresentados como os grupos face aos quais é importante preparar uma intervenção educativa intercultural.

Completada esta fase do projecto sobre a caracterização dos respectivos territórios e grupos étnicos, as equipas russas foram convidadas a destacar áreas de intervenção prioritária num sentido intercultural, tendo contado com o contributo das equipas parceiras da União Europeia a nível de referentes científicos e políticos europeus (síntese em FCSH/UNL, 2015c). As áreas destacadas permitiriam o maior conhecimento de estratégias de intervenção endereçadas a diferentes públicos-alvo, da esfera governamental ao sistema educativo, dos media à população em geral e à população etnicamente diversa em particular. Estas áreas focavam, sobretudo, os campos da educação (educação ao longo da vida, bilinguismo na educação, programas educativos para imigrantes) e da diversidade étnica, cultural e religiosa (modelos de integração de imigrantes, extremismo e xenofobia online, diálogo religioso).

Devemos ainda referir que, num projecto desta tipologia, é necessário comunicar em permanente tradução linguística entre delegações. Esta tarefa torna-se particularmente complexa por se tratar de uma área temática em que os conceitos-chave não estão consolidados ou são inexistentes na língua russa (como é exemplo o conceito de interculturalidade), o que implica incluir no debate conceitos mediadores. O conceito mediador que merece maior destaque neste projecto é o de tolerância, que não está isento de uma visão dominadora e assimilacionista sobre a diversidade étnica, linguística, cultural e religiosa, e cuja promoção acabou por se transformar no foco das actividades de uma parte significativa das IEP.

\section{Diálogos europeus para o desenvolvimento intercultural: Lisboa sob tradução}

No caso concreto do projecto ALLMEET, a tradução e integração de sugestões direccionadas ao desenvolvimento intercultural partiram de um diálogo estruturado entre as entidades parceiras russas, a entidade coordenadora italiana e as entidades parceiras de programa (União Europeia - UE) portuguesa, escocesa e holandesa. A rede de parceiros da UE foi estruturada de modo a conciliar áreas de experiência e potenciar o fortalecimento de colaborações prévias. Em Itália, a equipa coordenadora sediada na Universidade de Bolonha, partindo do Departamento de Educação em colaboração com o Departamento de Linguística, tem ligações históricas a uma das principais redes de centros interculturais, de trabalho de reconhecido mérito desenvolvido com imigrantes e seus descendentes, e de estruturação da educação intercultural entre escolas e serviços municipais. Na Escócia, a equipa da Universidade de Glasgow sintetiza as 
prioridades educativas e a promoção de estratégias criativas para a resolução de conflitos e a promoção do diálogo inter-religioso. Na Holanda, o European Centre Valuation of Prior Learning especializa-se no reconhecimento e validação de competências, auxiliando na construção de instrumentos para a valorização dos percursos biográficos e da formação ao longo da vida. Em Portugal, a equipa da FCSH/UNL resulta da integração entre Ciências da Educação e Sociologia, conciliando a experiência prática em escolas multiculturais, formação inicial e contínua de professores e a investigação essencial e aplicada nos campos da educação, do território e de populações em mobilidade.

Considerando o território de enquadramento da equipa portuguesa e os objectivos de partilha de experiências e competências entre as equipas parceiras, foi organizada uma visita de estudo intitulada ALLMEET in Lisbon '15. Esta visita teve como objectivo destacar boas práticas identificadas na Área Metropolitana de Lisboa no que respeita à educação e ao diálogo intercultural, bem como à resposta política num contexto pós-colonial de sistema migratório lusófono e de iniciativas premiadas de inclusão (não obstante a existência de experiências de exclusão) (Vieira et al., 2016a).

Podemos partir da ideia de tradução, entendida como acto de interpretação e reapresentação em nova língua/quadro de entendimento (a partir de Ferrarotti, 2011), enquanto chave para a partilha intercultural visada pela visita supracitada. A ideia de tradução sugere que a apresentação de boas práticas não significa a sua transposição para outro contexto territorial; porém, elas podem ser observadas, interpretadas e sugerir novas direcções para o desenvolvimento intercultural em contextos diferenciados.

A visita ALLMEET in Lisbon '15 (Vieira et al., 2016b) contemplou várias iniciativas sob tradução intercultural, das quais destacamos:

- o seminário internacional "Intercultural dialogue: learning, speaking, and sharing" (23/11/2015, FCSH/UNL), no qual foram apresentadas comunicações sobre fundamentos interculturais na Rússia; língua, narrativas e inclusão social; da multi- à interculturalidade; e relevância social e política de projectos internacionais;

- o seminário "Intercultural Study \& Research CICS.NOVA" (26/11/2015, FCSH/UNL), no qual investigadores deste centro de investigação partilharam a sua experiência sobre mediação intercultural, trabalho linguístico em educação, tutoria e educação multi- e intercultural;

- a visita ao Alto Comissariado para as Migrações, I.P. (ACM), onde foi apresentado o modelo de Centros Nacionais para o Atendi- mento a Imigrantes (CNAI), considerando a evolução das políticas de inclusão no sentido de uma provisão intergovernamental de serviços direccionados a imigrantes (onde estão representados os Ministérios da Educação, Saúde, Segurança Social, o Serviço de Estrangeiros e Fronteiras, a Autoridade para as Condições do Trabalho, entre outros), para além da apresentação de dados actualizados sobre migrações em Portugal;

- a Migrantour, criada no âmbito de um projecto europeu promotor de visitas guiadas por imigrantes, promovendo o conhecimento do território com residentes de origem estrangeira, no caso lisboeta decorrente na Mouraria, o bairro com maior diversidade étnica da capital portuguesa;

- a visita à Escola Secundária de Camões, que contemplou uma apresentação da unidade curricular Português Língua Não Materna (PLNM) e do Centro para a Qualificação e o Ensino Profissional (CQEP Camões), potenciando o debate sobre o alcance e a importância de iniciativas de educação linguística, validação de competências e requalificação profissional para imigrantes e refugiados em diferentes ciclos de vida.

Consideramos que esta visita ALLMEET in Lisbon '15 permitiu dar a conhecer um conjunto de ofertas territorialmente ancoradas para o atendimento e a integração da diversidade étnica, cultural e linguística, através de modelos formais e de programas da sociedade civil e da rede escolar que revelam um sentido inclusivo e empoderador das minorias.

Esta abordagem não significa, porém, que não existam boas práticas no contexto da Federação Russa ou que as partilhas promovidas pelas delegações da UE signifiquem uma necessária transposição para as estruturas políticas e educativas russas. A alteração da legislação e a criação de associações e outras organizações envolvidas no desenvolvimento de um diálogo entre diferentes grupos étnicos ou religiosos são exemplos elencados pelos parceiros russos nos seus relatórios sobre o estado da arte em cada território. Estes relatórios reflectem o caminho percorrido em matéria de construção de políticas educativas e sociais face à diversidade cultural nos territórios representados e na Federação Russa em geral. Contudo, um projecto da tipologia do ALLMEET - de partilha de boas práticas e implementação de estratégias educativas inovadoras em países vizinhos da UE - significa, antes, uma tentativa de aproximação e de diálogo entre entidades territoriais que se querem parceiras, ainda que atravessando um momento histórico de conflito e esmorecimento da relação UE - Federação Russa. 


\section{Pistas para a inclusão de minorias no desenho de territórios educativos interculturais}

Anteriormente foram apresentados os principais desafios interculturais e grupos minoritários identificados nos diferentes territórios das delegações parceiras russas, e ilustrados alguns exemplos de boas práticas interculturais a partir do caso português (integrado na rede ALLMEET em diálogo UE - Federação Russa). Que pistas podemos então sugerir, a partir deste projecto, sobre a inclusão de minorias no desenho de territórios educativos interculturais?

Nesta secção propomos o aprofundamento da discussão em torno de quatro pistas. Como primeira pista, e considerando que o conhecimento de um dado território implica ultrapassar uma visão directa sobre as suas evidências ou sobre aspectos comunicados, mas efectivamente desconhecidos, consideramos necessário não só desenvolver uma problematização subjacente ao desenho de cada território educativo intercultural, mas também capacitar as equipas ancoradas nesse território ao nível de chaves de leitura dos desafios territoriais e de novos percursos potenciais face aos desafios identificados. Na segunda pista, com ponto de partida na partilha de propostas interculturais sob tradução permanente ao nível linguístico e conceptual, destacamos a necessidade de identificar diferentes visões sobre as finalidades da educação e respectivo enquadramento de grupos minoritários. Na terceira pista, partindo do caso português, premiado pela evolução dos seus modelos de integração, mas continuando a delimitar alguns territórios educativos segundo princípios de exclusão, propomos discutir a questão dos territórios educativos prioritários. Na quarta pista, articulada com a questão anterior, propomos discutir e reenquadrar o princípio da interculturalidade em contexto de desigualdades sociais.

Como vimos, o campo conceptual da educação intercultural abarca reflexões amplas que passam por questões jurídicas e organizacionais, estruturas e processos sociais, valores, conceitos relacionais, educativos e respeitantes ao campo da diversidade social (FCSH/UNL, 2015a). Ao nível organizacional, a questão do território potencia uma delimitação do espaço físico e social de referência para o desenho e a estruturação dos serviços educativos, dando prioridade ao diálogo na diversidade cultural.

O conhecimento de diferentes dimensões territoriais e comunitárias assume-se, assim, como um referente importante para o desenho de territórios educativos interculturais. Para melhor enquadrar o seu desenho torna-se necessário questionar:

- O que determina a delimitação de um dado território educativo?
- Há algum passado de desafios interculturais neste território? Se houver, como é que os desafios e opções de intervenção foram evoluindo?

- Existem políticas públicas para questões relacionadas com a diversidade, tais como migrações, cidadania, grupos e línguas minoritárias? Caso existam, qual o seu conteúdo e perspectiva face à gestão da diversidade?

- Qual a visão de desenvolvimento endereçada a diferentes níveis operacionais (federal, nacional, regional, local) no que respeita à educação e a grupos sociais diferenciados? Como é que se promove ou limita a possibilidade de constituir um território educativo intercultural a partir destes níveis?

- Quem são os actores sociais e as instituições mais activos no prosseguimento de metas interculturais?

- Que projectos interculturais têm vindo a ser desenvolvidos? São projectos educativos formais ou não-formais?

- Quais as situações informais, não intencionais, em que a interculturalidade pode ser desenvolvida em determinado território?

- O que falta, em determinado território, para o desenvolvimento da interculturalidade? Quais as prioridades de intervenção?

- Quais os públicos-alvo destas áreas prioritárias de intervenção?

Não há uma receita unívoca, mas sim diferentes possibilidades de desenvolvimento a partir do objectivo de desenhar territórios educativos interculturais. Estas possibilidades relacionam-se com diferentes perspectivas sobre finalidades e objectivos da educação, entre mediação, emancipação e monitorização, quando os grupos minoritários representam - ou são encarados como - desafios territoriais tais como os que têm sido percepcionados nos contextos russos.

Consideramos, de seguida, três perspectivas sobre finalidades educativas que implicam diferentes enquadramentos dos grupos minoritários. As finalidades da educação podem ser vistas, entre outras leituras, como (1) intrínsecas ao processo educativo, ainda que estabelecendo uma relação contextual (com o território, redes existentes e desafios sociais decorrentes) através da mediação; (2) vocacionadas para a emancipação social, considerando os contextos educativos enquanto contextos políticos nos quais os princípios democráticos devem ser desenvolvidos; (3) dependentes da compreensão das causas dos desafios sociais que subjazem aos contextos educativos, permitindo um trabalho sobre essas causas e a construção de novos percursos de conhecimento.

John Dewey (Sources of a Science of Education, 1929, in Gambôa, 2004: 40-42) desenvolveu 
uma reflexão importante sobre finalidades e valores educativos, considerando-os intrínsecos à própria educação. Tal não significa isolar a educação das condições sociais, ou separá-la do cerne da mudança social. Significa, sim, recusar que haja uma ordem externa ao que a educação deveria ser - uma vez que, para Dewey, o processo educativo, na sua integridade e continuidade, deve determinar as suas próprias finalidades. Esta leitura tende a afastar-se da reflexão sobre relações políticas de poder e sua influência na educação. Dewey optava por priorizar a mediação, encarada como interacção terapêutica direccionada para a pacificação dos sujeitos de uma mesma comunidade ética, aos quais é concedido um mesmo direito de crescimento pessoal com respeito pela sua individualidade.

Autores como Henry Giroux e Michael Apple (in Cabanas, 2002: 316-318) desenvolveram perspectivas críticas sobre o papel da educação para a emancipação social, reconhecendo mais claramente uma dimensão política da educação. Apple questionou o papel da escola e da sua influência na reprodução de classes sociais, desigualdades de género e preconceitos raciais, criticando a transmissão cultural prevalecente na educação formal através de mecanismos subtis, mas eficazes, ao exemplo do currículo oculto. Apple e Giroux propuseram currículos que invertessem a ideologia dominante, abrindo espaço para outras ideologias e culturas não dominantes. Giroux destacou o papel da educação como esfera pública democrática, um espaço social em que as pessoas possam manifestar a sua opinião crítica através de diálogos que contribuam para a construção de equidade, justiça e democracia.

Edgar Morin (2002), nas suas lições para uma educação do futuro, dedicou a sexta lição à aprendizagem da compreensão. Morin considerou que a compreensão estava ausente das propostas educativas na viragem do milénio, sendo que o seu desenvolvimento requereria uma necessária reforma nas mentalidades. Segundo o autor, só a compreensão mútua entre as pessoas, tanto em relações de proximidade como entre estranhos, poderá provocar uma evolução das relações humanas para além do estado bárbaro de incompreensão. Nesse sentido, Morin considera necessário estudar a incompreensão nas suas raízes, modos e efeitos, não focando os sintomas mas sim as causas do racismo, xenofobia e preconceito.

Os três contributos apresentados não são os únicos percursos possíveis, contudo ilustram diferentes modos em que a educação pode ser concebida e desenvolvida. Estas perspectivas não são mutuamente exclusivas, mas podem ajudar a perceber se o desenho de um dado território educativo se pauta mais por objectivos de pacificação/ /mediação, politização/emancipação, ou observação/ /monitorização.
A definição de territórios prioritários a partir dos seus traços de exclusão ou densidade de diferença não corresponde necessariamente ao que temos procurado reflectir como sendo territórios educativos interculturais. A proposição da interculturalidade implica um trabalho em diferentes tipos de territórios, não se cingindo a territórios estigmatizados, visualizados como "gueto", onde se concentram minorias socioculturais sob desvantagem socioeconómica.

Os territórios especiais para a intervenção social e educativa, tais como os franceses Zones d'Éducation Prioritaires (ZEP) e os portugueses Territórios Educativos de Intervenção Prioritária (TEIP), têm sido criticados pelo seu labelling de determinados contextos como desvantajosos, contribuindo para experiências sociais e educativas de insucesso (OCDE, 2010). No caso português, a constituição destes territórios representou um esforço ambicioso de política educativa para o combate à exclusão social. No entanto, algumas críticas e sugestões de visão mais ampla foram sendo suscitadas: ao nível da política educativa, procurar resolver o problema da exclusão social através da educação (de crianças) pode ser um ponto de partida erróneo, se considerarmos que a exclusão social está proximamente relacionada com questões económicas/do meio laboral; ao nível do trabalho pedagógico de escola e turma, a visão desvalorizada de vários stakeholders, particularmente dos professores, sobre alunos dos TEIP, é criticável e pode estar relacionada com menores hipóteses de sucesso escolar; ao nível da regulação local da política educativa, o desenvolvimento desde uma visão de território escolar para território educativo deveria ter aberto mais direcções de desenvolvimento, contribuindo para questionar as limitações da escola enquanto contexto educativo (Canário, 2004).

Salientamos, por fim, que enfocar exclusivamente territórios estigmatizados não significa restringir as propostas educativas a ideários ingénuos e benevolentes sobre o diálogo intercultural. É possível observar fortes desigualdades na estruturação do espaço social, designadamente entre matrizes classistas e culturais dominantes e minoritárias (Silva, 2008). Estas desigualdades têm conduzido, por exemplo, à progressiva perda de diversidade linguística, no cenário actual de crescimento e globalização das línguas dominantes. Em contexto urbano, as desigualdades sociais continuam a ser observadas após processos de renovação em contextos de forte diversidade social e étnico-cultural. Aí se verifica que as políticas de social mixing não são garantia de equidade social (Lees, 2008), pois ainda que valorizadas pela nova classe média face ao seu capital simbólico étnico/cultural, elas não se traduzem numa menor diferenciação entre classes sociais coabitantes. 
Retomando o campo educativo, a proposta intercultural não é desprovida de críticas e chamadas de atenção a algumas lacunas na sua transposição para a prática, particularmente a partir da questão das desigualdades. Por exemplo, pode observar-se a relação entre o projecto intercultural e determinados juízos morais através do foco em valores e discursos como os que se relacionam com a tolerância. O foco na tolerância é um dos exemplos que nos permite equacionar até que ponto a proposta intercultural se realiza num plano de desigualdade, dominação e hierarquias, através de uma maioria que tolera, condescendente e benevolente, a presença de determinadas minorias. Esta desigualdade - conjunto de sistemas de estratificação social de base étnica que se acrescentam a questões de classe social e género, entre outras - é um dos pontos débeis do conceito de interculturalidade enquanto modelo de organização da vida social em contextos multiculturais, ao enfocar o objectivo de diálogo intercultural podendo descurar dimensões socioeconómicas e jurídicas essenciais à emancipação das minorias (Malgesini e Giménez, 2000).

\section{Conclusões}

No âmbito do projecto ALLMEET, as delegações parceiras russas procederam à caracterização dos diferentes territórios nos quais pretendiam implementar Plataformas Educativas Interculturais, para as quais consideraram como prioritário o desenvolvimento de recomendações políticas e educativas face à diversidade étnica, cultural e religiosa. Esta diversidade respeita a um conjunto de grupos populacionais diferenciados, não correspondendo a uma visão de emergência multicultural que se resuma ao crescimento das populações imigrantes, mas sim englobando diferentes religiões, línguas e grupos étnicos indígenas dos territórios considerados ou de outros territórios da Federação Russa.

Face à identificação destes grupos minoritários e das acentuadas diferenças entre os territórios considerados, as delegações parceiras da União Europeia procuraram contribuir para o diálogo intercultural através da identificação de boas práticas políticas e educativas potencialmente traduzíveis. No caso português, foi organizada uma visita de estudo em Lisboa onde, para além de seminários de disseminação científica e de práticas de mediação e educação intercultural em Portugal, se procurou dar a conhecer um conjunto de ofertas territorialmente ancoradas para o atendimento e a integração da diversidade étnica, cultural e linguística, particularmente através do modelo CNAI (ACM) e de programas da sociedade civil e da rede escolar que revelam um sentido inclusivo e empoderador das minorias.

Este diálogo significa uma partilha de boas práticas e de experiências e, sobretudo, uma refle- xão sobre as realidades em matéria de estruturas políticas e educativas em território russo a partir de observadores com experiência distinta, como é o caso das delegações da UE. Por outro lado, o diálogo vê-se complexificado pela necessidade permanente de tradução entre delegações, particularmente por se tratar de uma área temática em que os conceitos-chave não estão consolidados na língua russa (ao exemplo do conceito de interculturalidade, previamente inexistente), o que implica incluir no debate conceitos mediadores tais como o de tolerância, que não é isento de uma visão dominadora sobre a diversidade étnica, linguística, cultural e religiosa.

A partir deste projecto foi possível sugerir um conjunto de pistas sobre a inclusão de minorias no desenho de territórios educativos interculturais. Em primeiro lugar, privilegiando o conhecimento para lá das evidências de dado território, propusemos uma problematização subjacente ao desenho de cada território educativo intercultural. Em segundo lugar, identificámos uma pluralidade de visões sobre as finalidades da educação e seu enquadramento de grupos minoritários. Em terceiro lugar, considerando o caso português, sugeriu-se problematizar a questão dos territórios educativos prioritários enquanto territórios estruturados a partir de princípios de exclusão. Finalmente, propusemos discutir e reenquadrar o princípio da interculturalidade em contexto de desigualdades sociais.

A educação intercultural propõe finalidades ideais de diálogo entre culturas, mas parte de realidades contextualizadas da vida social, produtoras de maiorias e minorias significativas. A "vontade nominal" de incluir minorias (expressa no acolhimento de um projecto como o ALLMEET), tal como os direitos nominais de utilização de línguas minoritárias, já significam um certo nível de valorização e sinalização face à matriz cultural maioritária. Mas esta nominalidade intercultural pode não ser sinónimo da interculturalidade de matriz europeia, observando-se que as prioridades e referências para o desenho de Plataformas Educativas Interculturais em contextos russos não são necessariamente as mesmas entre si (quando por exemplo algumas regiões identificam como prioritário o diálogo inter-religioso, e outras centram a sua preocupação na questão étnica ou na existência de grupos sociais bastante distintos, como é o caso dos mais jovens ou dos estrangeiros), nem face às prioridades e referências dos contextos nacionais das delegações parceiras da UE.

O contexto russo sugere-nos, contra a antiguidade étnico-cultural de Portugal e da velha Europa, que a diversidade subjacente ao conceito de interculturalidade pode passar não só pela diversidade "vindoura", explícita na recepção de imigrantes, como também pela diversidade autóctone. Esta atenção para a diversidade interna do território de referência constitui, por si mesma, uma pista importante para 
a reflexão educativa. Esta pista permite resgatar o contributo da educação intercultural duplamente interventora face aos novos e velhos residentes, bem como estimular a atenção para diferentes níveis de diferença; uma atenção que se revela essencial para o desenho de territórios actualizados nos seus princípios inclusivos.

Finalizamos este artigo com a observação de que os princípios de inclusão e as experiências de exclusão fazem parte de um mesmo continuum, não se tratando de um binómio mutuamente exclusivo nem se referenciando a territórios com marcas 100\% utópicas ou distópicas. Centrar a atenção unicamente nas boas práticas inclusivas é um risco que pode contribuir para a desvalorização das desigualdades sociais observáveis no território em questão, como tem sido assinalado à abordagem da interculturalidade. Uma abordagem territorialmente ancorada sobre o princípio inclusivo da educação permite considerar os desafios e ponderar os recursos existentes, reflectindo criticamente sobre as boas práticas políticas e educativas, mas também sobre experiências exclusivas observáveis em sociedades plurais não igualitárias.

\section{Referências bibliográficas}

APPADURAI, A. (1996), Modernity at Large. Cultural Dimensions of Globalization, Minneapolis e Londres, University of Minnesota Press.

BAPTISTA, L. (2016), "Para lá das evidências. Uma reflexão sociológica sobre como observar as realidades territoriais", in F. L. Machado, A. N. Almeida e A. F. Costa (orgs.), Sociologia e sociedade. Estudos de homenagem a João Ferreira de Almeida, Lisboa, Mundos Sociais.

CABANAS, J. M. Q. (2002), Teoria da educação. Concepção antinómica da educação, Porto, ASA.

CANÁRIO, R. (2004), "Territórios educativos e políticas de intervenção prioritária: uma análise crítica", Perspectiva, 22 (1), pp. 47-78.

FCSH/UNL (Primary contributor); KFU; KIPPPE-RAE; MGPU; SibFU; NArFU; MarGU; UNIBO (Deliverable contributors and reviewers) (2015a), Intercultural Glossary, D2.3, WP2 - Analysis of the Existing Knowledge, Practices and Policies, ALLMEET - Actions of Lifelong Learning Addressing Multicultural Education and Tolerance in Russia, EU/Tempus.

FCSH/UNL (Primary contributor) (2015b), Report on Comparative Analysis and Benchmark, D5.2, WP5 - Quality assurance, ALLMEET - Actions of Lifelong Learning Addressing Multicultural Education and Tolerance in Russia, EU/Tempus.
FCSH/UNL (Primary contributor) (2015c), Overall Framework for the Assessment of the Quality Assurance, D5.3, WP5 - Quality assurance, ALLMEET - Actions of Lifelong Learning Addressing Multicultural Education and Tolerance in Russia, EU/Tempus.

FERRAROTTI, F. (2011), L'empatia creatrice. Potere, autorità e formazione umana, Roma, Armando Editore.

GAMBÔA, R. (2004), Educação, ética e democracia. A reconstrução da modernidade em John Dewey, Porto, ASA.

GENOVESE, A. (2003), Per una pedagogia interculturale, Bolonha, Bononia University Press.

LEES, L. (2008), "Gentrification and Social Mixing: Towards an Inclusive Urban Renaissance?", Urban Studies, 12, pp. 2449-2470.

MALGESINI, G. e C. G. Giménez (2000), Guía de conceptos sobre migraciones, racismo e interculturalidade, Madrid, Los libros de la catarata.

MORIN, E. (2002), Os sete saberes para a educação do futuro, Lisboa, Instituto Piaget.

NEWBY, H. (1980), Community. Bloc 3 Comparison and Change, Walton Hall, Melton Keynes, Open University Press.

OCDE (2010), OECD Economic Surveys: Portugal, 2010 (16), OECD Publishing.

SILVA, M.C.V. (2008), Diversidade cultural na escola: encontros e desencontros, Lisboa, Colibri.

TRAMMA, S. (1999), Pedagogia sociale, Milan, Guerini e Associati.

URBANO, C.; I. Vieira; M.C.V. Silva e L. Baptista (2016), "Promoting Interculturalism through Non-Formal Approaches - Proposing a Framework to Observe and Analyze Intercultural Initiatives", in I. Vieira, C. Urbano, M. Vieira da Silva e L. Baptista (orgs.), Intercultural Dialogue: Learning, Speaking, and Sharing. Proceedings of the International Seminar and Study Visit ALLMEET in Lisbon'15, Lisbon, CICS.NOVA, pp. 74-83.

VIERA, I.; C. Urbano; M.C.V. Silva e L. Baptista (2016a), "Overview on Intercultural Issues in Portugal", in I. Vieira, C. Urbano, M.C.V. Silva e L. Baptista (orgs.), Intercultural Dialogue: Learning, Speaking, and Sharing. Proceedings of the International Seminar and Study Visit ALLMEET in Lisbon'15, Lisbon, CICS.NOVA, pp. 23-30.

VIEIRA, I.; C. Urbano; M.C.V. Silva e L. Baptista (2016b), "ALLMEET in Lisbon'15: Report of the Study Visit.", in I. Vieira, C. Urbano, M. Vieira da Silva e L. Baptista (orgs.), Intercultural Dialogue: Learning, Speaking, and Sharing. Proceedings of the International Seminar and Study Visit ALLMEET in Lisbon'15, Lisbon, CICS.NOVA, pp. 102-112. 
Recebido a 01/08/2016. Aceite para publicação a 18/10/2016.

Inês Vieira (ines.vieira@fcsh.unl.pt)

Cláudia Urbano (claudia.urbano@fcsh.unl.pt)

Maria do Carmo Vieira da Silva (mcvs@fcsh.unl.pt)

Luís Baptista (luisv.baptista@fcsh.unl.pt)

Universidade Nova de Lisboa, Faculdade de Ciências Sociais e Humanas, Centro Interdisciplinar de Ciências Sociais (CICS.NOVA). Edifício I\&D, Avenida de Berna, 2, 1069-061 Lisboa, Portugal. 